\title{
EDITORIAL
}

\section{Traditional Versus Integrated Medical Education}

\section{BY Said Oraby}

Traditional medical education gives priority to large volumes of academic work and memorized knowledge. The traditional undergraduate medical curriculum $3+3$ ' has been followed over many decades in Egypt and includes basic medical sciences (anatomy, biochemistry, physiology, pathology, etc.) followed by clinical sciences (medicine, surgery, ob/gyn etc.). Basic science knowledge is taught in the first three years while clinical skills are provided over a period of the next three years.

In fact, a barrier between basic and clinical sciences exists. A major disadvantage of this type of curriculum format is that the learners forget the basic science knowledge when they enter into clinical phase. Thus, it is viewed as inadequate curriculum to prepare the future physicians for twenty first century ( Cook et al., 2006 and Cook \& O'Brien, 2010).

Many graduates complained about the overload and irrelevance of many lectures in the early years of their course, particular in biochemistry. There ere many different views about how they integrated this science teaching into understanding disease processes, and many didn't feel it was made relevant to them at the time they learned it (Watmough et al., 2009).

Integration in medical education is important because medical practice itself requires a great deal of integration (Loftus, 2015). Globally, the bar between basic and clinical sciences has been broken down to develop concepts of knowledge with clinical application which promotes retention of knowledge and acquisition of repetitive skills 
(Finnerty et al., 2010). There is a demand that, beyond a thorough understanding of applied anatomy and pathophysiology, medical graduates should possess knowledge across the basic and applied sciences, be experts in different areas of medical skills, and have exemplary attitude (Maeshiro et al., 2010).

Harden et al. (1984) described the integrated medical curriculum. The term was supported by many medical education organizations in American, UK and the Australian Medical Colleges. They stated that an integrated curriculum establishes significant linkages between the subjects or skills that are mainly addressing various subject areas to improve the learning experiences. Moreover, it allows opportunities for all the stakeholders to think outside the box.

Six education strategies have been identified relating to the curriculum in a medical school. Each issue can be represented as a spectrum or continuum: studentcentered/teacher-centered, problem-based/information-gathering, integrated/disciplinebased, community-based/hospital-based, elective/uniform and systematic / apprenticeship-based. The factors supporting a more towards each end of the continuum are presented for each strategy. Newer schools tend to be more to the left on the continuum, established schools more to the right. Each school, however, has to decide where it stands on each issue and to establish its own profile. This SPICES model of curriculum strategy analysis can be used in curriculum planning or review, in tackling problems relating to the curriculum and in providing guidance relating to teaching methods and assessment (Harden et al., 1984).

Why do we need integration in Egypt?

Egyptian medical institutions have started to develop integrated medical curricula in order to harmonize with the global concept in medical education. Integration is needed to avoid the information overload that is associated with the traditional curriculum where learning was delivered as a series of discipline blocks over concerned with detail and with little recognition of the links between subject and topic areas that are required to make the knowledge created available for use and application in new situations. Integration deals more with principles and concepts which can be used to explore and understand novel problems and allow new solution to be achieved. 


\section{References}

1. Cook M, Irby DM, Sullivan W, and Ludmerer KM.(2006): American medical education 100 years after the Flexner report. N Engl J Med., 355(13):1339-1344.

2. Cooke M and O'Brien BC. (2010): Calls for reform of medical education by the Carnegie Foundation for the Advancement of Teaching: 1910 and 2010. Acad Med., 85(2):220-227.

3. Finnerty EP, Chauvin S, Bonaminio G, Andrews M, Carroll RG, Pangaro LN. and Flexner R (2010): The role and value of the basic sciences in medical education. Acad Med., 85(2):349-355.

4. Harden RM, Sowden S AND Dunn WR. (1984): Educational strategies in curriculum development: the SPICES model. Med Educ., 18:284-297.

5. Loftus S (2015): Understanding Integration in Medical Education. Medical Science Educator; 25(3):357-360

6. Maeshiro R, Johnson I, Koo D, Parboosingh J, Carney JK, and Gesundheit N (2010): Medical education for a healthier population: Reflection on the Flexner report from a public health perspective. Acad Med., 85(2):211-219.

7. Watmough S, O'Sullivan $H$ and Taylor D (2009): Graduates from a traditional medical curriculum evaluate the effectiveness of their medical curriculum through interviews. BMC Medical Education; volume 9, Article number: 64 